Relmecs, diciembre 2018 - mayo 2019, vol. 8, no. 2, e043, ISSN 1853-7863

Universidad Nacional de La Plata. Facultad de Humanidades y Ciencias de la Educación.

Centro Interdisciplinario de Metodología de las Ciencias Sociales.

Red Latinoamericana de Metodología de las Ciencias Sociales

\title{
La metodología biográfica narrativa y posibilidades en el ámbito del docente universitario
}

\author{
The biographical narrative methodology and possibilities in the university teaching field \\ Manuel Delgado-García \\ Universidad de Huelva, España \\ manuel.delgado@dedu.uhu.es
}

\section{RESUMEN:}

En este texto se reflexiona sobre varios aspectos ligados al enfoque biográfico narrativo como uno de los métodos pertenecientes al paradigma cualitativo y empleado cada vez con más asiduidad en la investigación social y educativa. Desde este planteamiento y sin intenciones prescriptivas, nos aproximamos a los orígenes del método biográfico narrativo, ligados más al ámbito social, para a continuación profundizar en los postulados, prácticas y críticas que otorgan consistencia e incertidumbre a su aplicabilidad científica; y finalmente, a raíz de todo ello, centrar la atención en las posibilidades que aporta al campo de la investigación educativa. Palabras Clave: Metodología biográfica-narrativa, Investigación educativa, Investigación social, Historia de vida.

\section{Abstract:}

In this text, we reflect on several aspects linked to the narrative biographical approach. This is one of the methods belonging to the qualitative paradigm. It is used increasingly more frequently in social and educational research. From this approach without prescriptive intentions, we approach the origins of biographical narrative method, more linked to the social area. Then we delve into the principles, practices and criticisms that provide consistency and applicability scientific uncertainty; and finally, as a result of this, we are able to focus on the possibilities it brings to the educational research field.

KEYWORDS: Biographical narrative methodology, Educational research, Social research, Life history.

\section{INTRODUCCIÓN}

La metodología biográfica narrativa se identifica como un planteamiento adscrito al paradigma de la investigación cualitativa y asociado tradicionalmente al ámbito de estudio de las ciencias sociales y humanas; se trata de una metodología cuyo recorrido presenta tres grandes bifurcaciones representadas por su evolución en Estados Unidos, en Europa y en Latinoamérica, a lo que han contribuido obras como las de Aceves (1999), Bolívar y Domingo (2006), Marinas y Santamarina (1993), Pujadas (2000), Goodson (1996, 2004), Goodson y Sikes (2001), Elder, Kirkpatrick y Crosnoe (2003), Hargreaves (1996, 2003), Denzin (1989), Clandinin y Connelly (1995), Connelly y Clandinin (2000), Bertaux (1988), Huberman (1989), Ferrarotti (2007), Lechner y Abrantes (2014), Cornejo, Mendoza y Rojas (2008), Josso (2004), Passeggi (2010, 2011), Nóvoa y Finger (2010), Souza (2008), Passeggi, Souza y Vicentini (2011), entre otros, aportando claridad y diversos puntos de vista en lo referente a los aspectos epistemológicos, teóricos y metodológicos más esenciales.

Si profundizamos en el contenido de estas obras, compartimos la opinión de Rivas (2010, p. 19) al afirmar que estamos ante "una opción de investigación en cierto modo diferente en las ciencias sociales y en particular en educación, que pretende hacer frente a las corrientes positivistas (y también algunas etnográficas) en su intento de segregar al sujeto del investigador". Por lo tanto, es la voz del sujeto la que articula el relato y le da el sentido oportuno para lograr una comprensión, al más alto nivel, por parte del investigador, lo que supone una característica diferencial de otras perspectivas interpretativas.

En esta línea, este trabajo sintetiza una revisión teórica realizada en la conformación de una tesis doctoral (enmarcada en el uso del paradigma del método biográfico narrativo) para aproximar al investigador a la realidad del docente universitario. En concreto, el artículo se inicia abordando el origen del método biográfico 
narrativo ligado a la investigación social para, a partir de ahí, profundizar en los fundamentos teóricos y metodológicos que otorgan consistencia a dicha metodología en su uso en investigación social pero también en la investigación educativa.

Es en el marco de la investigación educativa donde este trabajo centra una especial atención, con el objetivo de exponer las principales aportaciones que un método de naturaleza social facilita al marco de la investigación educativa; concretamente, se destacan las evidencias relatadas en investigaciones que han tenido como referente la figura del docente en diferentes niveles de la educación, pero sobre todo en la educación universitaria, dado que es uno de los niveles en los que:

a) Por una parte, este tipo de metodología aún no aparece como un recurso ampliamente utilizado y, por lo tanto, es preciso dar visibilidad a esas potencialidades que se extrapolan del marco de la investigación social.

b) Por otra parte, la educación superior está inmersa en continuas transformaciones que generan múltiples cambios en todas sus dimensiones, y es aquí donde el método biográfico narrativo emerge como un recurso con el que otorgar transparencia y visibilidad a las buenas prácticas que los docentes universitarios emplean como principales responsables de la promoción de dichas transformaciones.

\section{Punto de partida}

Se hace patente a través de numerosas investigaciones (Goodson, 2004; Bolívar y Domingo, 2006; Oliveira, Coharik, Pereira, y Barbara, 2006; Cid-Sabucedo, Pérez-Abellás y Zabalza, 2009; Hernández, Sancho, Montané y Sánchez de Serdio, 2009; López de Maturana, 2010; Grangeiro Gondim, 2012; Muñiz Terra, 2012; González-Monteagudo y Ochoa-Palomo, 2014; Rubilar Donoso, 2015; Delgado-García y Boza-Carreño, 2016; Hipchen \& Chansky, 2017; Passeggi, 2017; etc.) la importancia que el método biográfico narrativo cobra en la actualidad, hasta lograr integrarse en la dimensión cualitativa como diseño metodológico con entidad propia. Pero hasta llegar a esta situación, el enfoque biográfico narrativo ha pasado por diversas etapas que han determinado su posición actual dentro del marco de la investigación educativa.

Así pues, para ubicarnos en el marco del uso de este método en investigación social, como precedente podemos hablar de la sociología interpretativa moderna y las meditaciones de Dilthey sobre el estatuto de las "ciencias del espíritu" que dejaban su impronta en algunos seguidores de la sociología próximos al "paradigma de la comprensióny su método” (Denzin, 1989, p. 13). A ello le suceden otros tres hitos relevantes que serán los que consolidan el método:

\subsection{La Escuela de Chicago}

La aparición de la narración de experiencias se encuentra ligada inicialmente a la Escuela de Chicago (1890). A través de esta institución, que abre sus puertas en 1892, se ponen de relieve los estudios de carácter social y antropológicos (cuyos temas principales fueron la inmigración y la delincuencia) dirigidos por A. Small, P. Radin y otros, que se muestran como una alternativa al positivismo y a la investigación social basada en el experimento y en la encuesta estadística (Argüello, 2014). Así, la Escuela de Chicago "reelaboró y dio forma de instrumentos científicos a documentos, experiencias y prácticas que hasta ese momento se habían considerado como insumos aptos para la literatura, la reflexión filosófica o la orientación ética pero no para la ciencia" (Moreno, 2009, parr.1); en concreto, se podría afirmar que el objeto de la investigación era:

La experiencia concreta, entendida como flujo social permanente y caracterizada por la ambigüedad y la subjetividad. En los estudios de Chicago encontramos un triple foco de interés: la explicación histórica y evolutiva de la vida de personas, grupos o unidades sociales; el desarrollo de la teoría; y los problemas metodológicos(González Monteagudo, 2008, p. 211). 
Vemos así cómo la tradición narrativa se retrotrae en el tiempo hasta finales del siglo XIX; pero será la publicación del tercero y último volumen de The Polish Peasant in Europe and America, de Thomas y Znaniecki en 1920, la que establezca un punto de partida del enfoque biográfico junto con la narrativa en el marco de las ciencias sociales y más concretamente en la sociología.

\subsection{La "Nueva" Modernidad}

Ya en el siglo XX (años 80), asistimos a un gran auge y reconocimiento científico de la investigación biográfica ligado a un potenciamiento del sujeto, motivado por:

Los crecientes cuestionamientos a las explicaciones reduccionistas de las ciencias y la radicalización de las urgencias de la vida legadas por la filosofía existencial de la posguerra, así como por los renovados conflictos de la segunda mitad del siglo XX y sus dramas acentuados en el correr del tercer milenio (Argüello, 2014, pp. 296-297).

No obstante, de forma paralela siguen existiendo numerosos altibajos en el desarrollo del enfoque dado que otros paradigmas, ligados a la investigación social, tratan de focalizar la importancia en elementos ligados directamente con el sujeto (como es el caso del materialismo y la infraestructura económica) y, por tanto, ponen en tela de juicio el valor que una escritura de base experiencial y autorreflexiva pueda aportar.

\subsection{El Movimiento postestructuralista}

Finalmente, para superar las críticas de los enfoques estructuralistas emergen una serie de nuevos paradigmas (Argüello, 2014) que vuelven a replantear la situación del yo y que sostienen, como afirma Corvez (2000, p. 11), que "la riqueza de la vida no proviene por entero del hombre que inventa sus manifestaciones (...). Lo concreto y lo vivido, el sujeto y su libertad, la conciencia individual, son también realidades que no se pueden menospreciar ni anular (...)". Se trata de entender que los sujetos sociales generan y dan significado a los acontecimientos que se producen en la sociedad y, por lo tanto, la realidad no es algo a descubrir sino que es una construcción por parte de los agentes participantes de la misma; es decir, "la ciencia deja de preocuparse por buscar la veracidad de las teorías formuladas y empieza a ocuparse de cómo los sujetos viven su propia cultura y, sobre todo, cómo la interpretan" (Rivas, 2010, p. 20).

En la actualidad el método biográfico narrativo se surte de unos paradigmas postestructuralistas que defienden el uso de los relatos, las memorias narradas o escritas, las autobiografías o la interpretación de documentos personales desde un plano interpretativo, para hacer extensible el potencial de dicha metodología en las ciencias sociales, más allá de la sociología (Güelman y Borda, 2014), y ofrecer plenas garantías en un ámbito tan relevante como es el marco educativo:

la razón principal para el uso de la narrativa en la investigación educativa es que los seres humanos somos organismos contadores de historias, organismos que, individual y socialmente, vivimos vidas relatadas. El estudio de la narrativa, por lo tanto, es el estudio de la forma en que los seres humanos experimentamos el mundo (...) la educación es la construcción y la re-construcción de historias personales y sociales (Connelly y Clandinin, 1995, pp. 11-12).

Como consecuencia de toda esta evolución, el método biográfico narrativo en España sufrió una importante transformación allá por los años $70 \mathrm{y}$, desde entonces, se ha venido mostrando como una de las estrategias más empleadas para analizar diversos aspectos de la educación formal, como pueden ser los cambios e innovaciones, la labor del estudiante, el curriculum, los espacios y tiempos en educación, etc., pero principalmente cobran especial relevancia los estudios sobre los docentes, en los que se ha venido trabajando sobresu vida cotidiana, aprendizaje de la profesión, ciclos de la carrera docente, pensamiento, actitudes ante los cambios y las reformas, desarrollo del currículo, formación permanente y desarrollo profesional (González Monteagudo, 2008; Bolívar, 2010; Delgado-García y Boza Carreño, 2016; Fernández Cruz, 2010; 
González Calvo y Barba, 2014; Oliveira, Coharik, Pereira, y Barbara, 2006; Passeggi, Souza y Vicentini, 2011; Grangeiro Gondim, 2012; Madinabeitia y Lobato, 2015; Sarasa, 2012; y otros); es lo que se ha denominado paradigma del pensamiento del profesor (teacher thinking).

Este paradigma es el que predomina en la investigación educativa a través del método biográfico narrativo en España. Mediante él se obtienen abundantes datos conducentes a mejorar los procesos de enseñanzaaprendizaje de los docentes, se analizan aspectos concretos y relevantes de la trayectoria personal y profesional, además de ofrecer una poderosa contribución a la mejora y desarrollo de la institución educativa. En concreto, en el caso de la educación superior, Marín (2005, p. 131) afirma que "el profesor universitario necesita conocerse a sí mismo, conocer y analizar su estilo docente, con el fin último de poder promover actitudes positivas hacia el cambio y el crecimiento profesional". Y es por esto que el enfoque biográfico narrativo es más que un recurso empleado para mejorar la formación, ya que permite al docente acceder a un proceso de reflexión profunda con el que exponer y poner en tela de juicio aquellas prácticas que emplea en el ejercicio de su profesión.

\section{INDAGANDO EN EL ENFOQUE BIOGRÁFICO NARRATIVO}

\subsection{Postulados teóricos}

Para una mejor comprensión de lo que supone hablar del método biográfico narrativo ligado al marco de la educación, se hace imprescindible definir las dos dimensiones que componen este enfoque de investigación. Así, siguiendo a Bolívar (2010, pp. 3-4) ha de entenderse el enfoque biográfico como:

la investigación que se ocupa de todo tipo de fuentes que aportan información de tipo personal y que sirven para documentar una vida, un acontecimiento o una situación social, que hace inteligible el lado personal y recóndito de la vida, de la experiencia social e identidades, del conocimiento adquirido. En él tienen cabida todas las metodologías de investigación cuya principal fuente de datos se extrae de documentos biográficos (personales o institucionales), que dan sentido a acciones o trayectorias vitales actuales, pasadas o futuras, a partir de las informaciones en las que se cuentan experiencias o historias desde la perspectiva de quien las ha vivido.

Mientras que el enfoque narrativo va a definirse como:

un enfoque de investigación en el que se marcan las pautas/formas de construir el sentido, a partir de acciones temporales personales, por medio de la descripción y análisis de los datos biográficos. El relato narrativo es -entonces- una forma específica de discurso organizado en torno a una trama argumental, secuencia temporal, personaje/s, situación...”.

A partir de estas aclaraciones conceptuales, se evidencia la necesaria dualidad entre lo narrativo y lo biográfico para el desarrollo de una investigación de corte cualitativo, en la que el objeto de estudio queda constituido por la figura del docente y, más específicamente, por el relato de su propia experiencia. Esta aclaración es importante de cara a exponer los principales postulados que otorgan unas señas de identidad propias al enfoque biográfico narrativo dentro del marco de la investigación educativa (Álvarez, 2010; López Suarez, 2011) y que, a partir de lo expuesto en el trabajo de Bolívar y Domingo (2006, parr.17), pueden sintetizarse en los siguientes:

- Narrativo. El conocimiento práctico, la experiencia o curso de la vida se expresa por medio de narrativas. La trama argumental y temporalidad configura el relato.

- Constructivista. El relato no se limita a representar la realidad, sino que la construye, en los modos como los humanos dan sentido a sus vidas y a su mundo.

- Contextual. Las narraciones biográficas y los episodios que éstas relatan, sólo encuentran sentido dentro de los contextos en los que son contadas y en los que se produjeron: social, cultural, institucional, etc. 
- Interaccionista. Los significados se adquieren e interpretan en función del contexto en el que se desenvuelven y en continua interacción con los mismos.

- Dinámico. La dimensión temporal es clave en el relato, por el propio concepto de desarrollo, se construye y reconstruye constantemente en un proceso continuo aunque no homogéneo.

A raíz de estos postulados, se puede afirmar que el enfoque biográfico narrativo sienta unas bases para considerarse como un nuevo diseño para hacer investigación en el marco de la educación. Y parece evidente que será labor del investigador dar un giro a su forma de trabajar para que los objetivos de sus actuaciones en educación se aproximen aún más a dar una respuesta a favor de la enseñanza. En esta línea, la Association Internationale des Histoires de Vie en Formation(citada en González Monteagudo, 2008), añade que en la actualidad el enfoque biográfico narrativo se considera como:

una práctica de investigación, formación e intervención, guiada por un objetivo innovador y emancipador, que pretende compaginar el trabajo individual del sujeto narrador de su vida con la dimensión colectiva propia de los seres humanos. En tanto que investigación, el objetivo consiste en la producción de conocimiento; en tanto que formación, la meta perseguida es contribuir a que los sujetos den sentido a su propia vida; en tanto que intervención, el fin consiste en contribuir a que las personas se impliquen en la acción social (p. 210).

\subsection{Dimensión práctica}

En referencia a los planteamientos teóricos que le otorgan consistencia científica en el marco de la investigación educativa, del mismo modo se puede hablar de los pilares metodológicos de los que hace acopio el enfoque biográfico narrativo y que le permiten acceder al objeto de estudio en particular. En concreto, hablamos de dos estrategias metodológicas básicas como son los relatos de vida y las historias de vida, las cuales han sido ampliamente definidas por trabajos como los de Moreno (2009); Aceves (1999); Álvarez (2010); Pujadas (2000); Josso (2004); Millamaci y Giménez (2006); Bolívar y Domingo (2006); Hernández, Sancho, Montané y Sánchez de Serdio (2009); Goodson (2003); Sandin (2003); Sancho et al. (2007); Sanz (2005); González Monteagudo (2008); Cornejo, Mendoza y Rojas (2008); Sanchidrián y Ortega (2011); Ferrarotti (2007); entre otros.

Siguiendo estos trabajos, podemos aventurarnos a definir los relatos de vida (life story) como una narración de carácter personal en la que el protagonista trata de reflexionar a través de un análisis lineal, en cuanto al tiempo y al discurso, acerca de lo social. Se trata de recoger la narración de la vida tal y como la persona la ha vivido o la cuenta, en relación a un aspecto de la realidad previamente seleccionado o por confirmar, por lo que este método acaba por sustentarse en la subjetividad que implica la narración emitida.

En el relato de vida, lo que interesa es ordenar lo que el sujeto nos cuenta y, este orden, se puede lograr a través de dos formas diferentes de organización del relato:

- Relatos de vida paralelos: "Este tipo de procedimiento utiliza las narraciones biográficas cuando el objeto de estudio consiste en unidades socio-demográficas muy amplias" (Pujadas, 2000, p. 145). Es decir, se refieren a trayectorias de vida que han transcurrido sin que por ello hayan tenido que converger ni generar vínculos entre sí (Sanz, 2005).

- Relatos de vida cruzados: "se trata de emplear los relatos de distintas personas pertenecientes a la misma generación, conjunto, grupo, territorio, etc., con el objeto de realizar comparaciones y de elaborar una versión más compleja y 'polifónica' del tema/problema objeto del interés de la investigación" (Aceves, 1999, p. 4).

Por otra parte, destaca el uso de las historias de vida (life history) en el seno del marco biográfico narrativo. Se presentan como una perspectiva de análisis única, que se caracteriza por mostrarse como una narración extensa de una experiencia de vida entera (como un todo), en la que el sujeto pone el acento en los aspectos 
que encuentra más destacados de su pasado y presente, y que al mismo tiempo le son relevantes para describir, entender o representar la situación actual (Sandin, 2003). Así, y al igual que ocurre con los relatos de vida, el objetivo de una historia de vida no va a ser el conseguir una validez o crédito de un acontecimiento, sino captar la visión que el sujeto tiene de sí mismo (tanto a nivel personal como profesional) y de su contexto (a través del uso de la palabra, gestos, sentimientos, creencias, reacciones, actitudes...) con el fin de generar una reflexión que le permita dar una respuesta más profunda en relación a lo investigado.

También se puede hablar de dos modalidades para clasificar las historias de vida (Pujadas, 2000), según sea el tipo de narración o relato que necesitemos:

- Historias de relato único: van a tener como condición indispensable la consecución de un único testimonio, que se muestre como representativo de todo el grupo social al que representa y que nosotros estudiamos. En este caso, el narrador abarca toda la existencia memorable y comunicable en la situación de investigación (se convierte en una autobiografía acompañada por un investigador). Este tipo de historias de vidas son las más difíciles de llevar a la práctica por la dificultad que entraña localizar un informante que disponga de todo el tiempo que se precisa y que disponga de todos los recuerdos que la investigación necesita; el resultado sería la elaboración de una historia de vida completa, en la que el papel del investigador:

no concluye con la elaboración del texto autobiográfico, sino que tiene que agregar un trabajo preciso de reflexión, crítica y contextualización del texto oral, en el marco sociohistórico correspondiente, con la finalidad de comprender el sentido propio y particular de la experiencia personal relatada por el sujeto en cuestión (Aceves, 1999, p. 4).

- Historias de relato múltiples: interesa recabar evidencia de carácter testimonial del ámbito personal, pero "también podría ser útil acceder a la evidencia perteneciente al ámbito colectivo (...); son estudios más amplios y requieren por lo general de una muestra cualitativa extensa, diversa y significativa del contexto histórico y cultural donde se halla inmersa" (Aceves, 1999, p. 3). En estos casos, se suele optar por construir historias a partir de un aspecto en concreto de la vida del narrador (una sola temática) y, por ende, el investigador se muestra como guía del proceso y encargado de generar una triangulación entre los datos obtenidos, con el fin de dar respuesta a los objetivos establecidos inicialmente.

Desde ambos planteamientos, parece evidente que el procedimiento de construcción de la narración viene organizado en torno a una trama o argumento, con una dimensión temporal, apoyado en unas relaciones sociales y un espacio concreto, para finalizar en un texto cuya elaboración puede verse alterada, en mayor o menor medida, por parte del investigador para acentuar los elementos que mayor atención suponen para el objeto de estudio.

Por otra parte, volviendo al terreno pragmático, desde el plano metodológico la consecución del relato narrativo va a tener como principal herramienta a la entrevista biográfica en profundidad. Esta es utilizada para canalizar la información a la que el investigador tiene acceso y, junto con el investigado, entrar así en contacto de forma sucesiva con el objeto de investigación.

A pesar de ser una técnica ampliamente abordada en el conjunto del paradigma cualitativo, desde el marco de la investigación biográfica narrativa se le atribuyen nuevas dimensiones que permiten adaptar su funcionalidad a los fines de este tipo de metodología (Alheit, 2012; Ruiz Blázquez, 2015). En este sentido, aunque es una técnica que demanda la interacción de al menos dos personas, en este caso, el investigador cobra un papel secundario y se va a limitar a inducir la narración, transcribirla y "retocar el texto final", siendo el investigado el que se torna protagonista de la narración de lo acontecido en su vida, convirtiendo esto en un proceso reflexivo de autodescubrimiento del significado que han tenido algunos de esos acontecimientos y experiencias. 
A nivel práctico, para mejorar la calidad de la información y enriquecer el proceso narrativo, en muchas ocasiones la entrevista biográfica suele apoyarse en una gran variedad de herramientas (Huchim y Reyes, 2013; Sandin, 2003; Moreno, 2009; Pujadas, 2000); en este sentido, González Monteagudo (2008) realiza una síntesis de aquellas que mejor complementan la funcionalidad de la entrevista biográfica y que permiten diseñar un proceso de investigación desde la máxima objetividad:

- Instrumentos de trabajo individual: diario personal, producción de un texto temático o creativo/ expresivo, búsqueda de testimonios materiales (fotografías de familia, cartas, objetos), creación de "objetos complejos", con uso simultáneo de varios lenguajes (“esculturas vivientes”, póster sobre la historia con imágenes y textos), instrumentos de papel y lápiz (perfiles cronológicos, biogramas, cuestionarios).

- Instrumentos de trabajo cara a cara: entrevista abierta, no directiva o semiestructurada, cuestionarios, métodos proyectivos (uso de imágenes, sonidos, símbolos, etc.).

- Instrumentos de trabajo colectivo: discusión oral a partir de documentos o de temas biográficos, autopresentación ante el grupo (oral, escrita, presentaciones cruzadas), uso colectivo de materiales proyectivos y de métodos evocadores (pp. 216-217).

A partir de todo esto, parece evidente que el empleo de esta técnica en investigación biográfica narrativa no implica obligatoriamente una recogida de datos o la obtención de un inventario de distintas conductas, competencias, experiencias, saberes... que posee una persona, sino que, como afirman Santamarina y Marinas, de lo que se trata es de "asistir o participar en la elaboración de una memoria que quiere transmitirse a partir de la demanda de uno, el investigador" (1995, p. 273). Lo cual no impide que podamos emplearla también como una técnica de recogida de datos y, por lo tanto, dependiendo de la funcionalidad que se otorgue a la entrevista, es posible distinguir diversas maneras de emplear el método biográfico narrativo en investigación (Millamaci y Giménez, 2006):

- La menos "biográfica" de las maneras, es la de aquellas investigaciones cuantitativas que emplean el relato biográfico como un recurso más para complementar o completar el resto de datos obtenidos, pero sin trascendencia.

- En un punto intermedio, se pueden encontrar investigaciones que otorgan al relato biográfico mayor funcionalidad, ya sea para ilustrar con ejemplos cualitativos y como corroboración anecdótica lo que se ha investigado por otras vías, o bien para indagar en ellos como fuentes de información desde las que acceder a su trasfondo.

- Finalmente, la "más biográfica" de las maneras de emplear el relato en la investigación tiene que ver con utilizar el propio relato biográfico como el eje central de la investigación; aquí, la narración expresada se convierte en el propósito del trabajo y su integridad le otorga consistencia y fiabilidad de cara a su validez científica.

Teniendo en cuenta todas las modalidades de plasmar el método biográfico narrativo en la investigación cualitativa y, si ponemos el foco de atención en el fenómeno educativo, podría afirmarse que esta metodología es una de las formas más interesantes para acercarnos al mismo, dándonos la oportunidad de conocer a sus protagonistas y llegar a comprender la apropiación que hacen de los fenómenos sociales, culturales y educativos. Como afirma Bolívar (2010, p. 14) “[el docente] recupera la autoridad sobre su propia práctica y el sujeto se expresa como autor de los relatos de prácticas, al tiempo que saca del anonimato, se le hace visible y muestra su saber profesional".

Fruto de esta presencia del método biográfico narrativo en educación, Agulló (2010) realiza una síntesis a partir de trabajos que han empleado el uso del relato biográfico. Este trabajo sirve para sacar a la luz las historias de: 
a) Protagonistas que por circunstancias ideológico-políticas han estado silenciados y marginados de la historia oficial.

b) Protagonistas oficiales de la historia: se trata de no ignorar a los que poseen una destacada presencia pública (publicaciones, cargos, funciones, etc.).

c) Protagonistas de las vanguardias pedagógicas: hay que dar presencia a los docentes que son referentes en la innovación y desarrollo pedagógico.

d) Protagonistas anónimos: es preciso abstraer del anonimato a todos aquellos docentes cuyos testimonios y trayectorias permiten entender variedad de prácticas educativas, conocer los obstáculos del presente y comprender la pertinencia de las políticas actuales.

La utilización de todos estos relatos en el ámbito de la investigación educativa tiene sentido si se enlazan las experiencias docentes, como saber personal, en un marco contextual más extenso sobre el cambio social y globalización, en el que localizar, interpretar y fundamentar dichos relatos (buscando nuevas interpretaciones, acerca de la construcción social del proceso de enseñanza)(Goodson, 2004); solo así se generará un saber hacer eficaz por parte del docente y, al mismo tiempo, se consagrará la funcionalidad de este tipo de metodología en el plano educativo.

En el caso de España, el nivel educativo donde con menor frecuencia se percibe el uso de esta metodología es en la educación superior. Hoy día son escasos los testimonios de vida de los docentes y, en la mayoría de los casos, tenemos sus aportaciones a nivel teórico en sus escritos en libros, revistas y publicaciones pedagógicas, pero no sabemos apenas nada acerca de su metodología didáctica, sus rutinas, sus relaciones con el alumnado... (Agulló, 2010); de ahí la importancia de conocer qué se está investigando sobre el docente en la educación superior a través de investigaciones que promueven el uso del método biográfico narrativo.

\subsection{1. ¿Qué se investiga sobre el docente en la educación superior?}

Como se ha apuntado hasta el momento, la trayectoria de la metodología biográfica narrativa en España no alberga un amplio bagaje de investigaciones ligadas al marco de la educación, como puede ocurrir en otros casos tales como en el mundo anglosajón. No obstante, se puede apreciar cierta evolución en el uso de este diseño metodológico en las últimas décadas y, fruto de ello, destacan las recopilaciones que Hernández (2004), Gijón (2010) o Rivas (2010) realizan en torno a trabajos que continúan líneas de investigación ligadas al método biográfico narrativo en educación, y cuya principal característica tiene que ver con la focalización del objeto de estudio en la figura del docente y, en menor medida, con los alumnos o con otros agentes implicados en la educación.

En este caso en concreto, a partir de trabajos como los de Bernal (2004), Álvarez (2010), Fernández Cruz (2012), Huchim y Reyes (2013), realizamos una síntesis sobre qué factores se investigan a través del método biográfico narrativo, cuando este se emplea para estudiar la figura del docente en la educación superior.

En primer lugar, destacan los trabajos que parten de la trayectoria o el itinerario profesional (espacio donde tiene lugar un encadenamiento cronológico de situaciones tales como experiencias tempranas, eventos significativos, etc.), poniendo el foco de atención en acontecimientos ligados a:

- La vida profesional: opción por la docencia; formación inicial; prácticas de enseñanza; socialización profesional; destinos; titularidades; cargos directivos o de gestión; discontinuidades en el desarrollo de la carrera; perfeccionamiento; destino actual.

- La vida privada: origen familiar en relación con la enseñanza; biografía escolar; modelos de referencia; matrimonio; hijos, discontinuidades; desarrollo de proyectos paralelos a la enseñanza.

- La vida institucional: proyectos realizados; innovaciones; conflictos, líderes/modelos en la institución. 
- Situaciones macrosociales: cambios de régimen político, reformas educativas nacionales; conflictos docentes nacionales; decisiones político-administrativas que afectan el colectivo profesional.

- La socialización profesional: interiorización de la cultura profesional (tres niveles: ajuste interiorizado, sumisión estratégica, redefinición); el conocimiento profesional; las creencias e imágenes sobre la enseñanza; la autopercepción; los estereotipos.

- La transformación biográfica: acontecimientos vitales pasados y formas actuales de pensamiento y comportamiento profesional (experiencias formativas, profesores significativos).

- Los incidentes críticos: fases y momentos críticos del desarrollo; eventos clave.

En segundo lugar, otro foco de atención es el marco del perfil profesional. Aquí, los trabajos van a centrar el interés en aspectos próximos a:

- La identidad profesional: autoimagen; autoestima; motivación profesional; desarrollo profesional; necesidades formativas.

- El conocimiento de la profesión: a nivel pedagógico (alumnos, contexto, curriculum), didáctico (contenidos) y práctico (valores, información); modelos de enseñanza.

- La cultura de la profesión: organización; visión o valores compartidos; compromisos; relaciones.

En tercer lugar, podría hablarse de un espacio destinado al estudio del ciclo vital. En este caso encontramos los trabajos que profundizan a través de historias de casos o historias de vidas en la trayectoria y el perfil profesional docente de forma integral.

Esta es una radiografía general de lo que podemos encontrar en la literatura científica a nivel nacional; no obstante, la evolución que está experimentando la educación superior con los recientes cambios provocados por la incursión en el Espacio Europeo de Educación superior y las reformas políticas, supone que predomine un panorama marcado por tendencias tales como la atención a la calidad docente, la diversidad, la crítica a los programas tradicionales de formación docente y su impacto en el aprendizaje del alumnado, o las múltiples visiones en el enfoque de los programas de formación inicial (Fernández Cruz, 2012). Todo esto se ve reflejado en un trasvase del foco de la investigación biográfica narrativa centrada en la figura del docente, pasando progresivamente de diseñar investigaciones ligadas principalmente al comportamiento, el conocimiento, la toma de decisiones o la reflexividad, a plasmar trabajos próximos al reconocimiento y a las posibilidades de transferencia que supone indagar en las buenas prácticas docentes (Fernández, Maiqués y Ábalos, 2012; Delgado-García y Boza Carreño, 2016; González, Guruceaga, Pozueta y Porta, 2010; Grangeiro Gondim, 2012; López de Maturana, 2010; entre otros), para así destacar ejemplos significativos y singulares de determinados casos que permitan comprender otros similares y, en lo posible, poder generalizar dichas prácticas para obtener de ellas un mayor rendimiento profesional.

\subsection{2. ¿Cómo sería el proceso de trabajo?}

Para abordar un diseño de investigación apoyado en el método biográfico narrativo, se torna imprescindible, por parte del investigador, poseer un notable conocimiento narrativo y un dominio óptimo del lenguaje que le permita, por una parte, interpretar aquellas acciones que emergen el discurso como una forma de elaborar significados y, por otra, que facilite al lector la construcción social de ese significado y su correspondiente evocación.

Además de esto, el investigador ha de tener presente una serie de nociones básicas a partir de la multitud de pequeñas variaciones existentes en función del tipo de objetivos que enmarquen la investigación. Pero, por regla general, se siguen unos patrones básicos de actuación que se repiten, en mayor o menor medida, y que le otorgan entidad propia al proceso. Siguiendo a Bolívar, Domingo y Fernández Cruz (2001), Hernández, 
Sancho, Montané y Sánchez de Serdio (2009) o Fernández Cruz (2010), establecemos como fases que han de estar presentes en cualquier diseño biográfico narrativo las siguientes:

Fase 1: autopresentación, biograma y diálogo informal de los participantes.

Una vez decidida la aplicación del diseño biográfico narrativo a través de algunas de las técnicas con las que este cuenta, a continuación se inicia el proceso de investigación y, lo ideal, es hacerlo con un relato inicial en el que, por un lado, se hagan las presentaciones oportunas tanto a nivel personal como profesional y, por otro lado, se negocie un acuerdo por el que se dan a conocer tanto las intenciones del investigador como la garantía del sujeto investigado de la veracidad de su relato y la autorización para su posterior difusión.

En definitiva, en esta primera fase, ha de quedar perfectamente delimitado un relato del encuentro (propósitos de la investigación; acuerdos alcanzados; enfoque metodológico; temporalización estimada; modo de participación en el proceso; ajustes en el relato: posibilidad de modificar frases, aportar nuevas interpretaciones, cambiar sentido de algunas frases, ampliar otras).

Fase 2: descripción mediante autoinformes, relatos biográficos, autoanálisis y recuerdos.

A continuación, se pasa a un segundo momento en el que, una vez que se ha descrito todo lo que supone la presencia del investigador y la del informante en la investigación, se procede a la narración del relato de este último.

Como ya se ha precisado, para proceder en esta fase, pueden emplearse diversos recursos que sirven de soporte para el diálogo que se está produciendo y que servirán de ayuda en la posterior reconstrucción de la narración por parte del investigador. Es en este punto donde ha de delimitarse la organización de toda la historia y de los temas que de ella emergen, junto con el escenario histórico en el que se desenvuelve.

Fase 3: cuestionamiento de lo sucedido en el análisis narrativo.

Una vez que tanto investigador como informante acuerdan que el primer esbozo de la narración está completo, se pasa a un momento donde el investigador cobra mayor protagonismo y se convierte en el encargado de trasladar la narración oral a un diseño escrito. Es en esta fase donde el tipo de diseño metodológico que se emplee condiciona al investigador a desarrollar un rol u otro (varía dependiendo del grado de manipulación) a la hora de trabajar con la narración. En todo caso, se ha de garantizar una literalidad estilística (sin llegar al extremo de una transcripción fonética), de tal modo que se refleje con cierta claridad el contenido expuesto por el narrador.

En el mismo sentido, a medida que se reconstruye el relato, el investigador ha de cuestionarse la información que tiene y han de percibirse todos los cambios que sean necesarios para seguir afrontando posteriores discusiones o imprimir variaciones que desvíen el discurso en otro sentido.

Fase 4: reconstrucción de toda la reflexión realizada por el informante.

Tras haber revisado y dialogado con el informante sobre su propia narración, a continuación se da paso a la reconstrucción de toda la reflexión presenciada y se realiza un balance general del relato, aportándolo (en el formato idóneo para el trabajo) en última instancia al problema de investigación; no obstante, el informante siempre ha de tener la opción de poder participar de este texto final.

El documento final debería acumular una serie de evidencias que le otorguen rigor en el plano del método biográfico narrativo y que Pujadas (2000) sintetiza en las siguientes:

(1) Ordenación cronológica y temáticamente de la información, (2) Recorte de las digresiones y reiteraciones, (3) Ajuste del estilo oral del informante lo mínimo posible para que sea aceptable por éste, (4) Introducción de notas a lo largo del texto que contextualicen y/o remitan a otras partes del texto, (5) Introducir, eventualmente, el testimonio de aquellas personas del universo familiar o social del informante que puedan permitir calibrar y dar perspectiva a la narración principal, (6) Realización de una introducción metodológica donde explicitar todas las circunstancias del proceso, (7) Es tan recomendable, como poco frecuente, que el investigador realice, al final del texto, una interpretación del significado del relato editado en el contexto de los objetivos temáticos y de la perspectiva teórica que han guiado la investigación (pp.140-141).

Con este esquema como base, y con los principios de respeto a la autonomía personal, confidencialidad y justicia como claves (Fernández Cruz, 2010), toda historia o relato de vida adquiere las dimensiones 
suficientes para su puesta en marcha; solo así se logrará que el diseño biográfico narrativo recoja la información pertinente y lo haga desde la perspectiva que marca este tipo de metodología, asegurando finalmente una fiabilidad en un proceso que, como ya se ha indicado, es complejo y reflexivo.

\section{Críticas al enfoque biográfico narrativo}

Esta complejidad del método biográfico narrativo de la que hablamos tiene su máximo exponente en dos variables fundamentales: de una parte, la subjetividad y la confiabilidad de la información que se deriva de la puesta de largo de su diseño y, de otra, el interés científico que pueda ofrecer la narración aportada por una sola persona.

Para dar una respuesta a estas críticas, la mayoría de los investigadores se posicionan en las propuestas marcadas por Bertaux (1981), recogidas en trabajos como los de Sandin (2000) o Bolívar y Domingo (2006):

a) En un primer momento, Bertaux trató de solventar el problema de la viabilidad e interés científico del relato de una sola persona; para ello propuso tratar los relatos de vida individuales como "relatos de prácticas" (deducir a partir de un relato el fondo histórico de relaciones sociales y profesionales que están en su base). Así basta con el relato de una sola persona, pues en cada persona está la cultura y cada persona está en su cultura.

b) De igual modo, al emplear los relatos biográficos como estrategia para recopilar datos, nos encontramos con el problema de la subjetividad y confiabilidad de los mismos. En esta línea encontramos dos opciones; por una parte utilizamos el concepto de saturación como solución: se trata de generar una triangulación (de personas, métodos y teoría) que garantice la validez interna de la información que rescatamos (cada nuevo relato no aporta nada nuevo) y contribuya a incrementar los resultados de la investigación y al desarrollo de la comprensión o del conocimiento de una realidad social; y por otra parte, se habla también de dar una explicación paso a paso de todo el proceso de investigación.

c) Una tercera crítica va a ir ligada a la necesidad de velar por la credibilidad del proceso de investigación. Para alcanzar este reto, es positivo promover el desarrollo de una observación participante, facilitar la participación de colegas mediante el juicio crítico y obtener una ratificación de toda la información por parte del informante para someterla, finalmente, a juicio público (confirmabilidad).

d) Por último, otro de los obstáculos tiene que ver con la fiabilidad y validez del instrumento utilizado (la entrevista biográfica en profundidad tiene un carácter abierto o semiestructurado, de manera que el informante puede tener mayor libertad en el discurso); se trata de revisar otros trabajos y seleccionar adecuadamente las fuentes, controlando los métodos de recogida y análisis de datos, de tal modo que respondan a los objetivos de la investigación y finalmente puedan ser triangulados.

Tomando en consideración todo lo expuesto hasta el momento, se puede afirmar que el método biográfico narrativo se ha hecho un hueco en el seno de la metodología cualitativa y, lo que es más importante, dentro de la investigación educativa. Cada vez se reciben menos críticas con respecto al empleo de la misma para hacer investigación.

\section{CONCLUSIÓN}

Para finalizar, Bolívar y Domingo (2006) aportan un comentario que recoge el sentido que ha de inspirar cualquier trabajo de investigación que utilice (a nivel educativo o social) el enfoque biográfico narrativo como diseño metodológico central: 
lo importante es el saber dialéctico que emerge en torno a un relato biográfico. Se supera el dilema entre veracidad del relato o intenciones que lo guían, entendiendo la memoria como un mecanismo de búsqueda de sentido de los hechos en función de la experiencia previa vivida, el contexto en el que se produce y la capacidad para interpretar la realidad actual, y no sólo como almacén de experiencias y recursos del que echar mano (parr. 102).

Es muy importante que esta idea cale entre los investigadores de la educación, pues el carácter personal que imprime este método no lo tiene cualquier otro con el que se pueda trabajar en este campo. Aunque, como todos, tiene unas ventajas (introduce en el universo de las relaciones sociales; permite conocer transformaciones personales y del grupo que pueden servir para controlar los resultados, minuciosidad y detalle en la información recopilada; posibilita homogeneizar la muestra para obtener mayor riqueza; etc.) y unos inconvenientes (dificultad para encontrar buenos informantes y para controlar la información; necesidad de analizar minuciosamente la información recopilada; exceso de actitud crítica del investigador, etc.) que le otorgan sus señas de identidad.

También es evidente que el enfoque biográfico narrativo permite interconectar diversas áreas afines al campo de la educación (sociología, filosofía, literatura, etnografía, psicología, etc.), lo cual es un factor que denota el potencial de cara a extrapolar la información e indagar en las diversas fuentes que inciden en la evolución de proceso de enseñanza y en el proceso de aprendizaje del ser humano.

En el caso de la educación superior, por todo lo argumentado hasta ahora, este tipo de metodología se torna muy positiva ya que, ahora más que nunca, el profesorado ha de abrirse más al resto de sus compañeros, no ya por decisión propia, sino porque los principios que persigue este nuevo enfoque que diseña la educación superior europea así lo indican. Se trata de compartir nuestra forma de trabajar, de reorganizar nuestras prácticas y de afrontar los retos desde una perspectiva más compartida y menos ensimismada en el "yo y mi método"; y, en esto, la investigación biográfica narrativa permite no solo contar, sino dialogar, negociar y reflexionar sobre el significado de una práctica profesional que queda al servicio de la comunidad.

Parte de los trabajos citados en este artículo sirven de fuente de inspiración y de reflexión para unos docentes universitarios cuya personalidad y profesionalidad atraviesan por diversas fases de transformación y consolidación a lo largo de su ciclo vital; es aquí donde los relatos de vida de otros docentes cobran un especial interés al actuar como desencadenantes de actuaciones que sirven para mejorar en su día a día y trasladar al estudiante una retroalimentación positiva y cargada de significación para completar una formación integral. Esta debería ser la finalidad de todo proceso indagatorio en la práctica profesional docente: repercutir no solo en el ejercicio docente sino también hacerlo extensible a las futuras generaciones, de manera que sean partícipes del bagaje cultural, social, político, económico, educativo, etc., que acompaña a la educación que reciben.

\section{Referencias BIBLIOGRÁfiCAS}

Aceves, J. E. (1999). Un enfoque metodológico de las historias de vida. Proposiciones, 29, 45-51.

Agulló, Ma . C. (2010). La voz y la palabra de los tesoros vivos: fuentes orales y recuperación del patrimonio históricoeducativo inmaterial. Educatio Siglo XXI, 28(2), 157-178.

Alheit, P. (2012). La entrevista narrativa. Plumilla Educativa, 10. 11-18. Recuperado de: http://revistasum.umaniza les.edu.co/ojs/index.php/plumillaeducativa/article/view/84

Álvarez, Z. (2010). Biografías profesionales de los profesores memorables: el impacto en la formación de profesores. En L. Porta y M. C. Sarasa (comp.). Estudios sobre las buenas prácticas y sus narrativas, (pp.159-179). Argentina: Universidad Nacional de Mar del Plata.

Álvarez, Z., Porta, L. y Sarasa, Ma . C. (2010). Itinerarios de la buena enseñanza a partir de los relatos biográficos docentes. Profesorado, revista de curriculo y formación del profesorado, 14(3), 89-98. Recuperado de: http:// www.ugr.es/local/recfpro/rev143ART6.pdf 
Argüello, A. (2014). La perspectiva biográfica en la investigación educativa. Una mirada a sus antecedentes, tendencias y posibilidades. Estudios Pedagógicos, 40(1),293-308. Recuperado de: http://www.redalyc.org/articulo.oa?id=1 73531772018

Bernal, J. (2004). La investigación biográfico-narrativa y la educación musical. Revista de Psicodidáctica, 17, 85-94. Recuperado de: https://dialnet.unirioja.es/servlet/articulo?codigo $=1130394$

Bertaux, D. (1981). Biography and society: The life history approach in the social sciences. London: Sage Publications.

Bertaux, D. (1988). El enfoque biográfico: su validez metodológica, sus potencialidades. Cuadernos de Ciencias Sociales: Historia oral e historia de vida, 18, 55-80. Recuperado de: http://preval.org/files/14BERTAU.pdf

Bolívar, A. (2010). La investigación biográfica narrativa en el desarrollo e identidad profesional del profesorado. En J. González Monteagudo (ed.), Entre formation, identité et mémoire: Les histoires de vie en Espagne (pp. 59-96). Paris: L=Harmattan.

Bolívar, A. y Domingo, J. (2006). La investigación biográfica y narrativa en Iberoamérica: Campos de desarrollo y estado actual. Forum: Qualitative Social Research, 7(4). Recuperado de: http://www.qualitative-research.net/in dex.php/fqs/article/view/161/357

Bolívar, A., Domingo, J. y Fernández Cruz, M. (2001). La investigación biográfico-narrativa en educación. Enfoque y metodología. Madrid: La Muralla.

Cid-Sabucedo, A., Pérez-Abellás, A. y Zabalza, M. A. (2009). Las prácticas de enseñanza declaradas de los "mejores profesores" de la Universidad de Vigo. RELIEVE, 15(2), 1-29. Recuperado de: http://www.uv.es/RELIEVE/v 15n2/RELIEVEv15n2_7.htm

Clandinin, D.J. y Connelly, F.M. (1995). Teachers' Professional Knowledge Landscapes. Nueva York: Teachers' College Press.

Connelly, F. M. y Clandinin, D. J. (2000). Narrative inquiry. Experiencie and story in qualitative research. San Francisco: Jossey-Bass.

Cornejo, M., Mendoza, F. y Rojas, R. (2008). La investigación con relatos de vida: pistas y opciones del diseño metodológico. Psykhe, 17(1), 29-39. Recuperado de: http://www.scielo.cl/pdf/psykhe/v17n1/art04.pdf

Corvez, M. (2000). Los estructuralistas. Buenos Aires: Amorrortu.

Delgado-García, M y Boza Carreño, A. (2016). La importancia de «aprender a enseñar» en la titulación de enfermería. Reflexiones biográficas de un médico con alma de educador. Educación Médica, 17(4) ,170-179. Recuperado de: https://doi.org/10.1016/j.edumed.2016.04.005

Denzin, N. K. (1989). Interpretative Biography. Newbury Park: Sage.

Elder, G., Kirkpatrick, M. y Crosnoe, R. (2003). The emergence and development of life course theory. En J. Mortimer y M. Shanahan (Eds.), Handbook of the Life Course (pp. 3-19). New York: Kluwer Academic/ Plenum Publishers.

Fernández Cruz, M. (2010). Aproximación biográfico-narrativa a la investigación sobre formación docente. Profesorado, Revista de Currículum y Formación de Profesorado, 14(3), 17-32. Recuperado de: http://www. ugr.es/ recfpro/rev143ART1.pdf (Error 8: El enlace externo www.ugr.es/ recfpro/rev143ART1.pdf debe ser una url) (Error 9: La url www.ugr.es/ recfpro/rev143ART1.pdf no esta bien escrita)

Fernández Cruz, M. (2012). Aportes de la aproximación biográfico-narrativa al desarrollo de la formación y la investigación sobre formación docente. Revista de educación, 3(4),11-36. Recuperado de: http://fh.mdp.edu.ar /revistas/index.php/r_educ/article/view/82

Fernández, A., Maiqués, J. M. y Ábalos, Á. (2012). Las buenas prácticas docentes de los profesores universitarios: estudio de casos. REDU: Revista de Docencia Universitaria, 10(1), 43-66. Recuperado de: http://red-u.net/re du/index.php/REDU/article/view/344

Ferrarotti, F. (2007). Las historias de vida como método. Convergencia. Revista de Ciencias Sociales, 14(44), 15-40. Recuperado de http://www.redalyc.org/articulo.oa?id=10504402

Gijón, J. (2010). Aprendiendo de la experiencia: relatos de vida de centros y profesorado. Revista de curriculum y formación del profesorado, 14(3), 5-16. Recuperado de: http://www.ugr.es/local/recfpro/rev143ed.pdf 
González, F., Guruceaga, A., Pozueta, E. y Porta, S. (2010). Una aproximación al conocimiento de una profesora universitaria, agente de buenas prácticas docentes, utilizando mapas conceptuales. Profesorado. Revista de Curriculum y Formación del Profesorado ,14(3), 117-130. Recuperado de: http://hdl.handle.net/10481/7232

González Calvo G. y Barba, J. J. (2014). Formación permanente y desarrollo de la identidad reflexiva del profesorado desde las perspectivas grupal e individual. Revista de curriculum y formación del profesorado, 18(1), 397-412. Recuperado de: http://www.ugr.es/local/recfpro/rev181COL12.pdf

González-Monteagudo, J. (2008). Historias de vida y teorías de la educación: tendiendo puentes. Cuestiones Pedagógicas, 19, 207-232. Recuperado de: https://idus.us.es/xmlui/handle/11441/17078

González-Monteagudo, J. y Ochoa-Palomo, C. (2014). El giro narrativo en España: Investigación y formación con enfoques auto/biográficos. Revista mexicana de investigación educativa, 19(62), 809-829. Recuperado de: http:/ /www.scielo.org.mx/pdf/rmie/v19n62/v19n62a8.pdf

Goodson, I. F. (1996). Representing Teachers. Nueva York: Teachers College Press.

Goodson, I. F. (2003).Hacia un desarrollo de las historias personales y profesionales de los docentes. Revista Mexicana de Investigación Educativa, 8(19), 733-758. Recuperado de: http://www.redalyc.org/articulo.oa?id=14001908

Goodson, I.F. (Ed.). (2004). Historias de vida del profesorado. Barcelona: Octaedro.

Goodson, I. F. y Sikes, P. (Eds.).(2001).Life History Research in Educational Setting: Learningfrom Lives. Buckingham: Open University Press.

Grangeiro Gondim, D. (2012). Documentación narrativa de experiencias pedagógicas de docentes jubilados. Revista Educación y Pedagogía, 23(61), 123-132. Recuperado de: http://aprendeenlinea.udea.edu.co/revistas/index.ph $\mathrm{p} /$ revistaeyp/article/view/14026/12440

Güelman, M. y Borda, P. (2014). Narrativas y reflexividad: los efectos biográficos del enfoque biográfico. Revista Latinoamericana de Metodología de las Ciencias Sociales, 4(1), 1-16. Recuperado de: http://www.relmecs.fahce .unlp.edu.ar/article/view/relmecs_v04n01a03

Hargreaves, A. (1996). A vueltas con la voz. Kikiriki, 42(43), 28-34.

Hargreaves, A. (2003). Enseñar en la sociedad del conocimiento. Barcelona: Octaedro.

Hernández, F. (2004). Las historias de vida como estrategia de visibilización y generación de saber pedagógico. En I. F. Goodson (Ed.), Historias de vida del profesorado (pp. 9-26).Barcelona: Octaedro - EU B.

Hernández, F., Sancho, J. Ma., Montané, A. y Sánchez de Serdio, A. (2009). ¿Cómo los académicos españoles se enfrentan con el cambio? Respuestas desde una investigación de historias de vida profesionales. Informe Final de la investigación: Los efectos de los cambios sociales en el trabajo y la vida profesional de los docentes universitarios. Ministerio de Ciencia e Innovación. SEJ2006-01876/EDUC. Universidad de Barcelona. http://www.ub.edu /esbrina. Recuperado de: http://cecace.org/docs/proj-profuni/Hernandez_y_otros_2009.pdf. Consultado el $22 / 09 / 2011$

Hipchen, E. \& Chansky, R. A. (2017). Looking Forward: The Futures of Auto|Biography Studies. a/b: Auto/Biography Studies, 32(2), 139-157. doi: 10.1080/08989575.2017.1301759

Huberman, M. (1989). The professional life cycle of teachers. Teachers College Record, 91(1), 31-57.

Huchim, D. y Reyes, R. (2013). La investigación biográfico-narrativa, una alternativa para el estudio de los docentes. Revista Electrónica Actualidades Investigativas en Educación, 13(3), 1-27. Recuperado de: http://www.scielo.sa .cr/pdf/aie/v13n3/a17v13n3

Josso, M. C.(2004). Experiências de vida e formação. São Paulo: Cortez.

Lechner, E. y Abrantes, P. (2014). La investigación (auto)biográfica en Portugal: un mapeo y dos estudios. RMIE, 19(62), 859-883. Recuperado de: https://www.comie.org.mx/v1/revista/portal.php?idm=es\&sec=SC03\&\&su $\mathrm{b}=\mathrm{SBB} \&$ criterio $=\mathrm{ART} 62009$

López de Maturana, S. (2010). Historia de vida de buenos profesores: experiencia e impacto en las aulas. Profesorado: Revista de curriculum y formación del profesorado, 14(3), 11-16. Recuperado de: http://www.ugr.es/local/recfp ro/rev143ART10.pdf 
López Suarez, Mª G. (2011). La entrevista y su uso en el método biográfico. En A. Lopes, F. Hernández, J.M. Sancho y J.I. Rivas (Coords.), III Jornadas de Historias de Vida en Educación: A Construção do Conhecimento a partir de Histórias de Vida. Universidad de Oporto, Oporto: Grupo Esbrina. Recuperado de: http://hdl.handle.net/24 $45 / 47252$

Madinabeitia, A. y Lobato, C. (2015). ¿Puede el impacto de las estrategias de desarrollo docente de larga duración cambiar la cultura institucional y organizativa en educación superior? Educar, 51(1), 127-147. Recuperado de: http://dx.doi.org/10.5565/rev/educar.697

Marín, V. (2005). La narrativa-biográfica como estrategia para el estudio de la figura del docente universitario. Campo Abierto, 28, 129-142.

Marinas, J. M. y Santamarina, C. (Eds.) (1993). La historia oral: métodos y experiencias. Madrid: Debate.

Millamaci F. y Giménez V. (2006). Historias de vida y método biográfico. En I. Vasilachis (Coord.), Estrategias de Investigación cualitativa (pp. 175-212). Barcelona: Gedisa.

Moreno, A. (2009). Historias de vida e investigación. [En línea]. Recuperado de: http://miguelmartinezm.atspace.co $\mathrm{m} /$ historiasdevida.html

Muñiz Terra, L. (2012). Carreras y trayectorias laborales: Una revisión crítica de las principales aproximaciones teórico-metodológicas para su abordaje. Revista Latinoamericana de Metodología de las Ciencias Sociales, 2(1), 36-65. Recuperado de: http://www.memoria.fahce.unlp.edu.ar/art_revistas/pr.5218/pr.5218.pdf

Nóvoa, A. y Finger, M. (Orgs). (2010). O método (auto) biográfico e a formação. São Paulo: PAULUS.

Oliveira, B., Coharik, H., Pereira, C. y Barbara, D. (2006). Histórias de vida e autobiografias na formação de professores e profissão docente (Brasil, 1985-2003). Educação e Pesquisa, 32(2), 385-410. Recuperado de: http://www.scie lo.br/pdf/ep/v32n2/a13v32n2.pdf

Passeggi, Ma . C. (2010). Narrar é humano! Autobiografar é um processo civilizatório. En Silva Passeggi (Org.), Invenções de vidas, compreensão de itinerários e alternativas de formação (pp. 103-130). São Paulo: Cultura Acadêmica.

Passeggi, Ma . C. (2011). Aproximaciones teóricas a las perspectivas de la investigación (auto)biográfica en educación. Revista Educación y Pedagogía, 23(61), 25-40. Recuperado de: http://aprendeenlinea.udea.edu.co/revistas/ind ex.php/revistaeyp/article/view/14001.

Passeggi, Ma. C. (2017). Autobiographical Narratives in Education. a/b: Auto/Biography Studies, 32(2), 293-295. Recuperado de: http://dx.doi.org/10.1080/08989575.2017.1288932

Passeggi, Mª C., Souza, E. C. y Vicentini, P. P. (2011). Entre a vida e a formação: pesquisa (auto)biográfica, docência e profissionalização. Educação em Revista, 27(1), 369-386. Recuperado de: https://dx.doi.org/10.1590/S010246982011000100017

Pujadas, J. J. (2000). El método biográfico y los géneros de la memoria. Revista de Antropología Social, 9,127-158.

Rivas, J. I. (2010). Narración, conocimiento y realidad. Un cambio de argumento en la investigación educativa. En J. I. Rivas, y D. Herrera (coords.), Voz y educación: La narrativa como enfoque de interpretación de la realidad (pp. 17-36). Barcelona: Ediciones Octaedro, S.L.

Rubilar Donoso, G. (2015). Practices of Memory and the Construction of Research Testimonies. A Methodological Reflection about Self-Interviewing, Testimonies, and Social Workers' Accounts of Their Research. Forum: Qualitative Social Research, 16(3). doi: http://dx.doi.org/10.17169/fqs-16.3.2257

Ruiz Blázquez, J. L. (2015). Las entrevistas en profundidad y la biografía. Revista san Gregorio, (monográfico I), 48-55. Recuperado de: http://revista.sangregorio.edu.ec/index.php/RSANG/issue/view/4/showToc

Sanchidrián, C. y Ortega, F. (2011). Historias de vida, archivos de la memoria e historia de la educación. En J. I. Rivas, F. Hernández, J. M. Sancho y C. Núñez (Coords.), II Jornadas de Historias de Vida en Educación Sujeto, diálogo y experiencia (pp. 135-140). Universidad de Málaga, España: REUNI+D.

Sancho, J. M., Hernández, F., Creus, A., Hermosilla, P., Martínez, S., Giambelluca, V., Cid, A. y Duran, P. (2007). Historias vividas del profesorado en el mundo digital. Praxis Educativa, 11, 10-30. Recuperado de: http:// www.redalyc.org/articulo.oa?id=153112899002 
Sandin, M. P. (2000). Criterios de validez en la investigación cualitativa: de la objetividad a la solidaridad. Revista de investigación educativa, 18(1), 223-242.

Sandín, M. P. (2003). Investigación cualitativa en educación: fundamentos y tradiciones. Madrid: McGraw Hill.

Santamarina, C. y Marinas, J.M. (1995). Historias de vida e historia oral. En J. M. Delgado y J. Gutiérrez (eds.), Métodos y técnicas cualitativas de investigación en ciencias Sociales (pp. 259-285). Madrid: Síntesis.

Sanz, A. (2005). El método biográfico en investigación social: potencialidades y limitaciones de las fuentes orales y los documentos personales. Asclepio, 57(1), 99-115. Recuperado de: http://asclepio.revistas.csic.es/index.php/ascl epio/article/view/32/31

Sarasa, M. C. (2012). La narrativa biográfica como vehículo para explorar las trazas de la buena enseñanza. Revista de Educación, 3(4), 167-182.

Souza, E. C. (Org.). (2008). (Auto)biographie: écrits de soi et formation au Brésil. Paris: L'Harmattan (Coleção Histoire de Vie). 